Dance and body image: Young people's experiences of a dance movement psychotherapy session

${ }^{1}$ Sarah Grogan, ${ }^{1}$ Alison Williams, ${ }^{1}$ Sarah Kilgariff, ${ }^{2} \mathrm{Jill}$ Bunce, ${ }^{2} \mathrm{~J}$ ohanne Simone Heyland, ${ }^{2}$ Talia Padilla, ${ }^{2}$ Chloe Woodhouse. ${ }^{1}$ Lisa Cowap, $\&{ }^{3}$ Wendy Davies

${ }^{I}$ Staffordshire University, Stoke on Trent, UK

${ }^{2}$ University of Derby, Derby, UK

${ }^{3}$ Body Image Dance, Staffordshire, UK.

RUNNING HEADING: Dance and Body Image

Address correspondence to:

Professor Sarah Grogan

Psychology

The Science Centre

Leek Road

Stoke On Trent

ST4 2DF

Phone: $\quad$ +44 1782294271

Fax: $\quad$ +44 1782294986

email: $\quad$ s.c.grogan@s,staffs.ac.uk 


\title{
Dance and body image: Young people's experiences of a dance movement psychotherapy session
}

\begin{abstract}
This study was designed to investigate qualitatively young people's experiences of a dance movement psychotherapy session in relation to their body image. Seven young women and six young men all aged seventeen years old took part in a dance session based on a therapeutic intervention informed by dance movement psychotherapy. After the session they gave accounts of the experience in focus groups and interviews. Their accounts were analysed using an inductive thematic analysis. Three themes were identified: Connectedness, Lack of Self-consciousness, and Body Acceptance. The session impacted positively on these young men and women's body image, leading them to feel more connected to their bodies, freer and less self-conscious, and more accepting of their bodies after the session. The session itself was experienced as fun and relaxing and seemed to be equally effective for both men and women. It is concluded that future work needs to investigate the role of the facilitator and the school environment in producing these positive results but general findings suggest that this is a promising procedure for use with both young men and women in this age group.
\end{abstract}

Key Words: Dance movement psychotherapy; body image; thematic analysis; focus groups; interviews. 


\section{Introduction}

Dance movement psychotherapy has been found to be effective in reducing psychological distress in young people with mild depression (Jeong et al. 2005), to improve quality of life and body image in breast cancer survivors (Sandel et al. 2005), is widely used by therapists working with people with clinical eating disorders (Frisch et al. 2006), and has been used as an intervention with obese patients (Muller-Pinget et al. 2012). No work to date has focused on how young people from non-clinical populations experience dance movement psychotherapy in terms of body image, although other kinds of dance interventions have been found to reduce body dissatisfaction in young women from nonclinical populations (e.g. Burgess et al. 2006). The study reported here focused on the body image related experiences of a small group of seventeen-year-old men and women exposed to one session of dance movement psychotherapy.

Body image is defined in this paper as 'a person's perceptions, thoughts, and feelings about his or her body' (Grogan 2008: 3), and the cognitive element, relating to satisfaction with the body was the key focus in this study. Body dissatisfaction is defined here as 'a person's negative thoughts and feelings about his or her body' (Grogan 2008: 4). Body image is a concern for older adolescents, and both young men and young women have been found to have significant appearance concerns that affect the quality of their lives (Smolak 2012; Tykla 2011). Most studies find that young women in the UK generally want to be thinner (Grogan 2008) while young men in the 16-18 years age group may want to be more muscular (Grogan and Richards 2002). This can impact selfesteem and can be linked with health-damaging behaviours such as extreme dieting (Smolak 2012) and anabolic steroid use (Smolak and Stein 2010). Pressures to conform 
to the ideal are prevalent in older adolescent peer groups and teasing about weight and shape has been shown to predict body dissatisfaction (Menzel et al. 2010). Media exposure can be a particularly salient source of appearance-based information in older adolescence and has been linked to body dissatisfaction in girls and women (Grabe et al. 2008) and in boys and men (Bartlett et al. 2008), particularly in those who have internalised media-based body ideals (Smolak 2012). It has been suggested by researchers working within a positive body image framework such as Tykla (2011) that interventions that encourage body appreciation and acceptance of a range of body types are likely to be effective in promoting body satisfaction, and those working with an objectification theory framework (Fredrickson and Roberts 1997) have suggested that a focus on body function rather than aesthetics may be effective in increasing body satisfaction though reducing self-surveillance and self-objectification.

The session used in this study was designed to enable a focus on body function and body appreciation, following suggestions by Tykla (2011) and Fredrickson and Roberts (1997) and was drawn from the discipline of dance movement psychotherapy (Dosmantes-Alperson 1981; Payne 2006). Dance movement psychotherapy, with its focus on feeling rather than observing the body (Hornyak and Baker 1989), has the potential to reduce self-surveillance and objectification and to promote body appreciation and acceptance (Koch 2006). The dance movement psychotherapy session that we used attempted to facilitate an exploration of body image which focused on feeling, understanding and appreciating the body (Johnson 2007) and increased awareness of the body (Payne 2006). To produce the session we drew on the work of dance movement psychotherapists working in the field of body image such as Hornyak and Baker (1989), 
focusing on a functional understanding of the body. We wanted to ensure that participants were clear about the concepts involved so as part of the session we showed the participants a video that explained to them the rationale behind what we were asking them to do, including showing a young women dancing freely to show them what we meant by natural movement. Although body movement is often constrained by cultural pressures, we wanted these young people to move as an expression of themselves and how they were feeling rather than viewing their bodies as 'watched' appearance objects (Fredrickson and Roberts 1997). Dance movement psychotherapy has developed from Laban's philosophy whereby we gain richness from body movement when we relate this to our inner world (North, 1972).

We only exposed the young people to a one hour session because this was an exploratory pilot study. We wanted initial reactions and feedback that would enable us to develop a full intervention to be rolled out to young people within this age range. As part of the session, young people were encouraged to be aware of all parts of their bodies using exercises focusing on mindfulness of the body and the ways that the body is affected by emotion, to bring about an awareness of the process of moving in different ways and in different emotional states and awareness of the links between the different parts of the body, and also viewed a film where they were encouraged to understand the difference between 'natural' and 'watched' (North 1972) movement. They did exercises where they were encouraged to focus on each part of the body from the feet upwards and to note how each was linked to other parts through a series of movements and awareness exercises which enabled them to think about how their bodies felt rather than how they looked. The session was designed to maximise feeling, understanding and appreciation of 
the body, following Johnson (2007), and increasing awareness of the body following Payne (2006) to encourage body acceptance and body satisfaction (Tykla 2011).

Our initial aim was to investigate how dance movement psychotherapy was experienced by participants in relation to their subjective experiences of body image (how it impacted on their body perception, evaluation, and feelings relating to the body). We also used young people's accounts of taking part in the session to provide process information to help us to design a dance intervention that could be rolled out in the future to a larger sample of young people if it showed promise.

As experience of exercise sessions can be gender-linked (Duncan et al 2009; Smith et al. 2009) we looked in particular at how young men and women might experience the session differently. Although many authors have argued that women are under more social pressure than men to conform to cultural body ideals (Bordo 2003; Choi 2000; Fredrickson and Roberts 1997), there is good evidence that young men are becoming more concerned with the appearance of their bodies than formerly (Cafri et al. 2005; Cafri and Thompson 2007; Grogan 2008) and it was important to know how these

kinds of dance sessions were experienced by young men as well as in young women. This study is the first to investigate qualitatively how a dance movement psychotherapy session is experienced by young men and women from non-clinical groups in relation to their body image.

\section{Key Research Questions}

1. Is body satisfaction increased when young men and women experience a session of dance movement psychotherapy? 
2. How can we maximise acceptability and effectiveness of this kind of session for young men and women?

\section{Method}

\section{Participants}

In this study we focused on young people from a college in the UK who were selected through opportunity sampling rather than being chosen because they had poor body image as previous work such as the Burgess et al. (2006) study mentioned earlier. Many young people within the non-clinical population have appearance concerns (Grogan 2008; Smolak 2012) and we aimed to see whether these 'normal' concerns could be ameliorated through a session of dance movement psychotherapy. Thirteen young people aged seventeen years old took part in the study. We asked for volunteers from the student group and some came along with a friend and some did not. Six were male (pseudonyms Aaron, Dave, James, Jamie, Howard and Sam) and seven were female (Kate, Mae, Helen, Emma, Ann, Hope and Manda). All were volunteers selected through a further education college in the UK and all were white except for one young woman who identified as Asian. Each of them assigned themselves a pseudonym at the start of the study and these are used to identify participants below. We did not want to weigh or measure participants or to ask them to give their measurements as doing this at school can create appearance anxiety (Blood and Grogan 2011) and we wanted to avoid making participants feel anxious or over-concerned about their weight which might have detracted from the positive effects of the session. However, all appeared to be within the normal weight range for their height.

\section{Materials}


A list of focus group and interview topics covering general experiences of the dance programme, before-after comparisons of body image, possible improvements to the programme, user-friendliness of the programme, programme presentation and any problems with this, and any continued perceived barriers to positive body image. The list of topics was to be used as a guide for discussion rather than an exhaustive list and other relevant topics were also discussed as they arose. We also used the first 10 minutes of a Body Image Dance 123 video (http://www.youtube.com/watch?v=kL9HZlhKiZk), 13 large pieces of paper (6ft.x 4ft.), marker pens, six giant latex balloons (4ft.), and a foam football in the session.

\section{The Dance Movement Psychotherapy Session Facilitator}

The facilitator was a woman in her 30s who was trained in dance movement psychotherapy and was slender but dressed in loose workout clothes to avoid body exposure, and did not wear make-up for the sessions.

\section{The Session}

The session took part in a dance studio at the college and was designed following the work of dance-movement therapists working in the field of body image such as Hornyak and Baker (1989). Participants first viewed ten minutes of a specially choreographed film (http://www.youtube.com/watch?v=kL9HZlhKiZk) to clarify what was meant by 'natural' movement and to introduce them to dance movement psychotherapy. The film showed a young woman engaged in natural movement and also explained the key ideas behind dance movement psychotherapy. They then took part in a warm up exercise, and then in exercises to promote body awareness, understanding and enjoyment using props such as hula hoops. The music was from Penguin Cafe Orchestra - When in Rome by 
Simon Jeffes tracks 1-4. This was chosen as it did not have lyrics and was unlikely to be known by any of the participants. Mainstream popular music was avoided as it is often connected through music videos to specific dance styles and steps and also can be linked to biographical stores of memories and associations. There were no differences in the ways that the session was administered to young men and to young women. The timings and a fuller description of the session can be found in Appendix 1. Mirrors in the dance studio were covered during the session to avoid participants viewing themselves during the session and to encourage a focus on inner feelings and body function rather than outward appearance.

\section{Procedure}

Ethical clearance for the study was gained from University of Derby ethics committee. After gaining informed written consent, young people participated in the therapeutic dance session in college time. The young people were told to wear comfortable clothes that would enable them to move easily. They did not receive any kind of financial or course credit reward for their participation. Young women participated in the session on the first test day and young men on the second. Participants then took part in focus groups and interviews. Focus groups were carried out in groups of three or four, with two male and two female groups; divided along gender lines to maximize comfort and disclosure (Wilkinson 2008). Focus groups and interviews were facilitated by four female research assistants in their 20 s and were run in a quiet space in the college. Two facilitators ran each focus group and interviews were each run by one interviewer. Focus groups and interviews were audio-recorded with the permission of the participants and their parents. Focus groups lasted between 17 and 33 minutes. Interviews were scheduled 
for up to 20 minutes and the longest was 16 minutes long. In the focus groups, participants were asked to reflect on the experience of completing the session and any effect on their body image. They were told that we were piloting the task and any comments on how to make it more effective would be recorded, as would their views on the efficacy of the session as a way of improving body image in men and women. Participants were encouraged to discuss their views among themselves, with minimal input from the facilitator. Each participant then took part in an individual interview where they discussed the same issues with one of the research assistants. Individual interviews gave participants space to discuss issues that they may not feel comfortable discussing in a group. By the time the interviewees took part in the interviews, rapport had already been built up with the facilitators, so these interviews were used to ask about additional information that participants had not felt able to discuss in the focus groups. All the same questions were asked and we ensured that all participants had expressed all their thoughts and feelings on each topic before we moved to the next topic. Participants were debriefed at the end of the interviews and given contact details for the project managers should they wish any more information about the study.

\section{Data Analysis}

All interview data were transcribed, including the interviewer's speech. In the transcripts below, (.) is used to indicate a pause of less than one second. Pseudonyms are used below to protect the identity of the participants. Data from interviews and focus groups were combined for analysis (derivation of each quote is indicated below).

Transcripts were submitted to a thematic analysis broadly informed by the procedures of Grounded Theory (Strauss and Corbin 1990) and adopting a critical realist 
perspective. We recognise that it is possible to acquire an insight into people's experiences through their accounts, but also that we as researchers have a role in constructing knowledge (Madill et al. 2000; Willig 2008). The analysis summarised the accounts produced by the participants through the development of abstract theoretical themes which enabled us to integrate and explain the data. These abstract themes were based upon the identification of 'relations of similarity and difference' (Dey 1999: 63) and represent our agreed interpretations of what people said in our interviews and focus groups. All were defined after the case rather than being driven by our expectations of what might be important to our participants. The analytic process involved several phases of analysis in which we attempted to develop an understanding of how these seventeen year olds talked about the experience of taking part in the session. The analysis started with line-by-line open coding to identify initial descriptive themes. Axial coding was then applied, and relational sampling and constant comparison were used to modify, confirm and elaborate themes. This enabled us to combine similar and related themes and to investigate the relationships between them. Selective coding with systematic sampling from both sets of transcripts (focus groups and interviews) was used to confirm and verify the themes and to make changes where necessary. As part of this process, we examined negative instances and ensured that theoretical saturation had been achieved so far as possible and that no new themes emerged from the last few transcripts. This set of procedures was first carried out by the first, second and third authors on half of the transcripts picked at random. All three of these authors had an interest in body image but none were experts on dance movement psychotherapy interventions, and none had preconceived ideas about what to expect from participants' experiences of the session. 
Themes selected were then discussed and agreed between the first three authors. Once an initial model was produced, this was then discussed by all authors. All resulting themes and the model were agreed by all authors. Additional information on how to make this session maximally effective was also collected and is summarised under 'Practical Suggestions for How to Run the Session in the Future' after the thematic analysis below. Additional analyses were conducted following an initial review of this paper and only those themes directly linked with body image were retained at this point. The resulting three themes were again agreed by all the authors. The resulting set of themes represents the bulk of the data from these interviews and focus groups relating to body image.

\section{Results}

\section{Thematic Analysis Results}

Three key themes were developed that represented young people's experiences of the session. Each theme will be described below, supported by representative quotes from participants.

Theme 1: Connectedness

Accounts in this theme centred around feeling more connected with the body, being more aware of the body/body parts, being more aware of what the body could do, and understanding the body. Increased connectedness was linked to more positive body image.

Participants reported that they felt that the session had helped them to become more aware of certain body parts, which in turn helped them to appreciate them more and feel more positive about them. Being aware of certain body parts and appreciating their role made them feel more positive towards their bodies. For example: 
"Yeah definitely, the part of you, like your feet, that you don't really pay attention to, whereas now you're like actually pay attention to them, like how actually how they keep you there, how they keep you stable and everything" (Manda, Focus Group).

Participants reported that their feelings of control over their bodies improved during the session and that greater awareness of certain body parts led to increased feelings of control. For example:

"Yeah I do feel more in control of it now (.) 'cause now I know what things work together, and I know it sounds stupid, but where bits of your body are? So like your hips like, you have this thing where they're quite high up, but they're not, they're right by the top of your legs and stuff like that so it feels like more control over stuff like that" (Hope, Focus Group).

Several participants also noted that they had become more aware of what their bodies could do and how different body parts were linked together. This was found in both males and females as shown in these quotes from Ann and Dave below:

'I'm like more aware of how everything links in with each other (.) like, if you're using one part of your body how another part can also affect that movement” ( Ann, Focus Group).

“Like various muscles that you weren't that aware of before and just took for granted, you're more aware of now and I appreciate that more.” (Dave, Focus Group)

This increased understanding of the body and connection with the body was linked with positive body image and body acceptance (see Theme 3 below):

"I think the more you connect with your body (.) the more you'd accept the way you are kinda thing" (Katie, Focus Group). 


\section{Theme 2: Lack of Self-consciousness}

Accounts in this theme centred around being free to express themselves as they wished through the dance session and generally, and feeling less self-conscious in the session setting and more generally. This linked to increased body acceptance and reduced appearance orientation. Participants said that they felt much freer to be who they chose and that the session had reduced the importance they placed on other people's opinions and attitudes towards their bodies. For example Hope said that she was previously very conscious about the way she looked, and what people thought about her, whereas after the session she felt that her appearance was less important than who she was on the inside:

"I just thought they see it as how you look, but like they must like take into account like who you actually are, whereas like before I was like, you've gotta look your best and everything, but now it's like be yourself, you're in yourself, and if people like you for who you are then that's who it is, but it's not like what you look like" (Hope, Focus Group)

Similar reports came from young women and young men. For instance, James emphasised that the session had helped him to refocus away from worrying about what other people think, but to focus on what he personally wanted, for example in terms of what he wanted to look like:

"But I think this has really helped me to understand that it's not about what other people think, this is who I am, this is what I want” (James, Individual Interview).

Some participants said that they had started off the session feeling self-conscious but that this had dissipated as part of the process of being involved in the session: 
"Yeah it's like (.) at first before we did what we did, the intervention we've just done downstairs [Facilitator: Yeah] I was more bothered about what other people thought of me [Facilitator: Okay] when [pause] I shouldn't be, I shouldn't really be stressed about those kinds of things" (Katie, Focus Group).

Several participants linked the freedom that they felt during the session, and reduced appearance orientation back to when they were children who did not care about the look of their bodies. For instance, Dave said that participating in this session helped him to move away from self-consciousness and towards the kind of freedom and independence from worrying about appearance-related pressures that he had felt when younger:

"I mean in adolescence you're more self-aware and er (.) this workshop just helped us to get away from that a bit, so it was kind of going back to where you just didn't care really" (Dave, Focus Group)

This was also seen in the young women. For instance, Helen said that taking part in the session made her feel like a child again, again linking being a child with being free, and Hope linked how she felt during the session with being like a child whilst feeling an adult level of control:

"Yeah like when we were playing with like the balloon like ball things at the end, you felt very like childish again like back to like how you used to be, like running about, just like messing about with them, hitting them, and then like when we were like doing foot work and controlling like where your foot went and stuff, you felt quite grown up and like you were in control of how everything was. So it's sort of like making you feel as if like different parts of your body affect how you feel. Like running about and stuff makes you feel quite childish again” (Hope, Focus Group).

The feeling of being freer after the session did not seem to be gender-linked. Young women and young men reported feeling more free and less self-conscious both during and after the session. 
In general, young men were less self-conscious about their bodies before and during the session than young women, and men expected women to be more self-conscious:

"It's like things do say that girls are a lot more (.) self-conscious about themselves than boys" (Aaron, Focus Group).

The young women themselves also expected that men were less self-conscious about their bodies than young women:

“Cos I don't think boys are more [pause] boys are less bothered about the way they look kind of thing [Facilitator: Okay]. I think they're a lot less conscious about their bodies” (Katie, Focus Group).

\section{Theme 3: Body Acceptance}

Accounts in this theme centred around feeling confident about and accepting appearance, including avoiding making social comparisons to others who are stereotypically attractive. The session seemed to enable participants to feel more positive and accepting of their bodies. This was particularly the case for the young men who all said positive things about how they felt about their bodies after the session. For instance, in this quote from Sam:

“At the moment I am more confident about my body now like I realise that I don't really need to think, to care what other people think" (Sam, Individual Interview).

Young women reported that the session had made them more accepting of their bodies and more positive about them, although this was more marked for some than for others. For instance, Emma reported that the session had helped her to be more positive and accepting of her body:

"It's the same body but you kinda see it in a different way" (Emma, Focus Group).

Others, such as Helen, had experienced less marked changes and still felt insecure about their bodies though their experiences of their bodies had changed in more subtle ways: 
“Anything that I thought was negative before hasn't really changed, but the things that I was unaware of have got better if that makes sense" (Helen, Focus Group).

Young men and young women reported that although they still had body insecurities, they were more accepting of these. For instance, Ann pointed out that although her body insecurities had not changed, she now understood her body better which she saw as a positive thing:

“Any insecurities that I had hadn't changed, but things that I weren't aware about like that's that's good to discover that [Interviewer: Yeah] and it's not necessarily always a negative thing, discovering something new about yourself, if it's not the same as what everyone else thinks, it's not a bad thing" (Ann, Individual Interview).

James reported that although he knew that his body did not match up with his muscular, toned ideal, he could accept that:

“I think now I feel more comfortable with my body and my image, but I mean it still doesn't change the fact that I'd like to become like more bulkier and also more toned at the same time"( James, Individual Interview).

Sam suggested that although the session would not be a permanent solution to everyone's body insecurities it would help to alleviate these through making people more accepting of perceived flaws and more confident:

"I was slightly conscious before, I'm still probably gonna be slightly conscious like tomorrow like when I wake up, I'll have forgotten about it, but say if you repeated the workshop now over and over again, it would tell people not to be conscious about it about their bodies as much, and everyone'd be more happy. I wouldn't say it'd sort it out permanently, like I wouldn't like say cases but it'd certainly help everyone feel more confident about themselves" (Sam, Individual Interview).

\section{Practical Suggestions for How to Run the Session In The Future}

Participants were asked for their suggestions on how to make the session maximally effective. Suggestions included having a 'passionate' and 'enthusiastic' facilitator for 
the session, keeping the groups small, keeping genders separate, possibly having a male facilitator for the young men, having groups made up of people previously unknown (though young women would like one friend in the group), and keeping the numbers even. Although the music was not the kind of music they would normally listen to, it was 'invisible' to most of them during the session and was experienced as relaxing by some of the participants. The session was generally seen as effective and appropriate for both young men and young women, and although young women expected that young men would dislike parts of the session this was not found to be the case when the young men themselves were interviewed. For instance, in this quote from Howard:

"I think (.) yeah it was a really neutral sort of (.) it like study to have been done, so [Interviewer: Yeah] I think there was nothing really needed there's no barriers towards young men" (Howard, Individual Interview).

\section{Discussion}

Our first aim here was to see whether body satisfaction increased as a result of engaging in this session. Clearly the session was experienced positively by these young men and women in terms of body satisfaction and body acceptance. Young men and young women reported feeling more accepting of their bodies after being exposed to dance movement psychotherapy. Although young women were less confident and more critical of their bodies even after the session, supporting other work that has shown that women tend to have more appearance concerns than men at least until they are in their seventies (Grogan 2011), both young men and young women seem to have benefited from it in terms of more positive body image and higher levels of body satisfaction and acceptance. 
It is perhaps not surprising that connectedness came out as a key factor that participants felt had changed as a result of the session. Some of the activities used were specifically designed to enable participants to feel more connected to their bodies, reducing mind/body separation (Johnson 2007) and linking the mind with the body (Koch 2006). However, it was interesting that both young men and young women felt that previously ignored body parts had been integrated into their felt body and that they experienced more control of their bodies. Various authors have suggested that a key reason why exercise interventions may be effective in improving body image is that people feel that their bodies are more under their control after the intervention (Campbell and Hausenblas 2006). This session clearly enabled these young people to feel more control over their bodies which was linked in their accounts with being more accepting of the ways that their bodies looked.

Perceptions of freedom were increased as a result of the session, and several participants reported that they felt that they had been enabled to become 'childlike' during the session which they found freeing and enjoyable. Both young men and young women reported decreased self-consciousness about their bodies and lower levels of appearance orientation as a result of the session. Various scholars have argued that women's bodies are socially constructed as objects to be watched and evaluated, and that this is less the case for men (Bordo 2003) and authors working within an objectification theory framework have suggested that chronic viewing of the self as an appearance object may have negative effects on body image (Fredrickson and Roberts 1997) so reductions in self-consciousness may promote more positive body image if maintained after the session. Although young men and young women agreed that young women were in 
general more self-conscious than young men about their bodies, men were not free from body concerns and all reported some degree of self-consciousness. Objectification theory has primarily been related to women rather than men (Tylka and Sabik 2010). However, some of the young men in this study reported that they had felt 'observed' and critical of their bodies prior to the session and had become less self-conscious as a result of the session and felt that this reduction in self-consciousness had impacted positively on their body image. Further work can investigate whether this is found in other groups of young men. It is possible that increased pressure on young men to focus on their appearance (Cafri and Thompson 2007) means that this kind of session, focusing on feeling rather than observing the body and on body acceptance rather than body critique, is as relevant to young men as it is to young women and that Tykla's (2011) work on positive body image may have implications for men as well as women. Although young women interviewed here expected that young men would be alienated by the concept of a dance session, the men interviewed here reported no such alienation. Future work will show whether this generalises beyond this particular sample of men. These young men had volunteered for a study on dance, a non-stereotypically masculine activity (Fisher and Shay 2009), so may have less stereotypical masculine attitudes to their bodies and to dance than other young men of the same age.

As expected, the ideal body that young men and young women would like to attain was very different. Young men's ideal was muscular and toned (as seen in the quote above by James) whereas the young women's ideal was slender, supporting work by many previous authors (Cafri and Thompson 2007; Grogan 2008). Although women were more likely to be overtly critical of their bodies in this study, both young women 
and young men reported increased acceptance of their own bodies after the session linked with being critical of unrealistic body ideals, and there were no identifiable differences between men and women. Although they still had body insecurities, they were more accepting of these. Other work (Arbour and Martin Ginis 2006; Grogan et al. 1996) has shown that both men and women make upward social comparisons with the bodies of other men and women under some circumstances. This study showed that the tendency to make upward (negative) social comparisons can be reduced through this session, linking with increased acceptance of perceived 'flaws' in participants' bodies. Although they were clear that these perceived body problems had not gone away, they were more able to accept them after the session.

We also wanted to know how to facilitate this kind of session most effectively, to maximise effectiveness and acceptability for young men and women. Participants found the session enjoyable which is promising as there is evidence that more enjoyable interventions are likely to be adhered to better (Smith et al. 2009). The competence and enthusiasm of the facilitator were mentioned by several of the participants as key in the effect of the session. The role of the facilitator was important and the fact that she was seen as highly competent may have encouraged participants to engage better with the session than otherwise. Other work has found that people engage with and adhere to exercise interventions more effectively if they perceive the person administering the session to be high in relevant expertise (Pullen et al. 2009). Recommendations from the participants for developing the session included wanting more sessions and longer sessions, and some were unsure of the long-term benefits of having only one session. In general they preferred to be exposed to dance movement psychotherapy in a group rather 
than individually, ideally a group of mostly unknown people. The music was mostly ignored although it was seen as part of the relaxation process by some of the participants. No participants were negative about the music so something similar (calming orchestral music) will be likely to be useful for future interventions. Before we ran the study we wondered whether this kind of session would be seen as equally effective and acceptable for young men and young women, and we expected that men might not feel that a dance session was appropriate for them. However, these particular men were comfortable with all aspects of the session. Whether other young men are equally comfortable with this will be determined by future research.

\section{Limitations and Ideas for Future Research}

This study took place in a British college that was not particularly fitness orientated and where it could be expected that pressures to conform to body-ideals were prevalent (Wertheim and Paxton 2011). The session took place in a dance studio, and it may be that these kinds of environments promote particular pressures to conform to a 'fit' body ideal (Choi 2000; Petrie and Greenleaf, 2011). We did what we could to reduce pressures to focus negatively on the body through hiding mirrors and through the generally body-positive focus of the session, and also through the key aspects of the session itself where the focus was on body acceptance. It may be that holding this session in a dance studio led to particular sets of expectations in our participants and impacted on their experiences. Future work could investigate impact of this kind of session in other kinds of environments that may be less intimidating to those who do not consider themselves to be fit, and/or to conform to societal slender ideals (Grogan 2008). The facilitator was conventionally slender, but dressed in a way to avoid exposing her body to 
try to avoid body critique and social comparison on the part of the participants. Future research could replicate this study with a variety of session facilitators who embody and do not embody the slender ideal. Factors such as participants' previous experiences with dance and exercise, and their health and fitness levels may also influence experience of the session so need to be ascertained in future work.

Another potential criticism of this study was that participants were asked to report on the session directly after engaging in it, there may have been some subtle social pressure to report mostly positive outcomes. We tried to avoid this by having different people running the session and carrying out the focus groups and interviews, and by having young women of a similar age to the participants acting as interviewers to reduce the power differential between interviewees and interviewees, but the fact that comments were all very positive may mean that participants did not feel able to tell us anything very negative. Also, it may be that the kinds of young women and men who sign up for a dance session are predisposed to being positive about it. Future work could determine whether this is the case. The school setting may also have contributed to reticence about presenting negative reports and further work in non-school environments with similar interventions will be informative.

\section{Conclusions}

This study benefited from accessing in-depth experiences of the session from both young men and young women and it was useful to have data from both focus group and individual interviews as some participants clearly felt more able to disclose individually and some in the group settings. If we replicated this study we would certainly use both methods of data collection again. It was also useful to include psychologists and dance 
psychotherapists as part of our team for this project and we would encourage others to do likewise. Results need to be replicated with longer sessions, more sessions, and with larger groups of young men and young women in and out of school in exercise and nonexercise environments. However, in general this study shows that this kind of session has promise as a means of promoting positive body image for young women and men. 


\section{Acknowledgements}

This project was a part-funded through Body Image Dance by private sponsorship and the Big Lottery which paid for research assistants' time and travel and transcription costs.

Many thanks to the young people who were kind enough to take part in the pilot session and to discuss their experiences of the session with us. 


\section{Notes on Contributors}

Professor Sarah Grogan is Professor of Health Psychology at Staffordshire University. She is engaged in research in body image and health behaviours such as exercise and drug use.

Alison Williams is a PhD student and part-time Lecturer in Psychology at Staffordshire University. She is carrying out a $\mathrm{PhD}$ looking at appearance-focussed skin cancer prevention interventions, and is interested in body image and health promotion.

Sarah Kilgariff is a recent MSc Health Psychology graduate from Staffordshire University. Her postgraduate research focussed on the link between body image and cosmetic surgery.

Dr Jill Bunce has been programme leader for the MA in Dance Movement Psychotherapy course at Derby University for the last five years. She has lectured internationally and nationally and continues to practise as a Dance Movement Psychotherapist in the Derbyshire and Staffordshire area.

Johanne Simone Heyland has an interest in the application of dance and movement for therapeutic purposes. She has led expressive creative movement workshops in a variety of educational and clinical settings with all ages. She has a BSc in Psychology and is a Registered Dance Movement Psychotherapist and has her MA in Dance Movement Psychotherapy. 
Talia Padilla is currently studying the MA in Dance Movement Psychotherapy at the University of Derby. She graduated from Music Composition at the Universidad de Guadalajara, in Mexico.

Chloe Woodhouse is currently studying for her MA in Dance Movement Psychotherapy at The University of Derby. She graduated from London Metropolitan University with a BA in Performing Arts

Lisa Cowap is a part-time Research Methods lecturer and research assistant at Staffordshire University. She is currently engaged in research evaluating plagiarism software but her research interests are primarily in Health Psychology.

Wendy Davies is a solicitor who has is Chair of Body Image Dance which was formed in Staffordshire in 2011 to produce Dance 123, an original score and dance work intended as a basis for developing workshops for schools, youth groups and Arts for Health programmes. 


\section{References}

Arbour, K.P., and Martin Ginis, K., 2006. Effects of exposure of muscular and hypermuscular images on young men's muscularity dissatisfaction and body dissatisfaction. Body Image: An International Journal of Research, 3 (2), 153 162.

Bartlett, C.P., Vowels, C.L. and Saucier, D.A., 2008. Meta-analysis of the effects of media images on men's body image concerns. Journal of Social and Clinical Psychology, 159 (3), 337-344.

Blood, E. and Grogan, S., 2011. Children's perspectives on height and weight screenings. British Journal of School Health, 6 (10), 434-439.

Bordo, S. 2003. Unbearable weight: feminism, Western culture, and the body (Tenth Anniversary Edition). Berkeley: University of California Press.

Burgess, G., Grogan, S. and Burwitz, L., 2006. Effects of a 6-week aerobic dance intervention on body image and physical self-perceptions in adolescent girls, Body Image, 3 (1), 57-67.

Cafri, G.and Thompson, J.K., 2007. The Muscular Ideal: Psychological, Social, and Medical Perspectives. New York: APA.

Cafri, G. et al. 2005. Pursuit of the muscular ideal: physical and psychological consequences and putative risk factors. Clinical Psychology Review, 25 (2), 215239.

Campbell, A., and Hausenblas, H.A., 2009. Effects of exercise interventions on body image: A meta-analysis. Journal of Health Psychology, 14 (6), 780 - 793

Choi, P.Y.L., 2000. Femininity and the physically active woman. London: Routledge. 
Dey, I., 1999. Grounding Grounded Theory: Guidelines for Qualitative Inquiry. London: Academic Press.

Dosmantes - Alperson, E., 1981. Experiencing in movement psychotherapy. American Journal of Dance Therapy, 4 (2), 33-44.

Fisher, J., and Shay, A., 2009. When men dance: Choreographing masculinities across borders. New York: Oxford.

Fredrickson, B.L., and Roberts, T.-A., 1997. Objectification theory: Towards understanding women's lived experience and mental health risks. Psychology of Women Quarterly, 21 (2), 173-206.

Frisch, M.J., Franko, D.L. and Herzog, D.B., 2006. Arts-based therapies in the treatment of eating disorders. Eating Disorders: The Journal of Treatment and Prevention, $14(2), 131-142$.

Grabe, S., Ward, L. and Hyde, J.S. 2008. The role of the media in body image concerns among women: A meta-analysis of experimental and correlational studies. Psychological Bulletin, 134 (3), 460-466.

Grogan S., 2008 Body Image: Understanding body dissatisfaction in men, women and children ( $2^{\text {nd }}$ ed.). New York: Routledge.

Grogan, S., 2010. Gender and Body Image: Implications for Promoting Body Satisfaction, Sex Roles, 63 (9-10), 757-765.

Grogan, S., 2011. Body image development in adulthood. In: T. Cash \& L. Smolak, eds. Body Image: A Handbook of Research and Practice. New York: Guilford, 93101. 
Grogan, S., and Richards, H., 2002. Body image focus groups with boys and men. Men and Masculinities, 4 (3), 219-133.

Grogan, S., Williams, Z., and Conner, M., 1996. The effects of viewing same-gender photographic models on body-esteem. Psychology of Women Quarterly, 20 (4), $569-575$.

Hornyak, L.M. and Baker, E.K.,1989. Experiential Therapies for Eating Disorders. New York: The Guilford Press.

Jeong, Y.J. et al. 2005. Dance movement therapy improves emotional responses and modulates neurohormones in adolescents with mild depression, International Journal of Neuroscience, 115 (12), 1711-20.

Johnson, M., 2007. The meaning of the body. Chicago: University of Chicago Press.

Koch, S. C., 2006. Interdisciplinary embodiment. Implications for creative arts therapies.

In: S. C. Koch and I. Brauninger, eds. Advances in dance/movement therapy. Theoretical perspectives and empirical findings. Berlin: Logos, 17-28.

Madill, A., Jordon, A., and Shirley, C., 2000. Objectivity and reliability in qualitative analysis: Realist, contextualist and radical constructionist epistemologies. British Journal of Psychology, 91 (1), 1-20.

Menzel, J., Scaefer, L., Burke, N., Mahew, L., Brannick, M and Thompson, J.J., 2010. Appearance-related teasing, body dissatisfaction, and disordered eating: A meta analysis. Body Image, 7 (4), 261-270.

Muller-Pinget, S., Carrard, I., Ybarra, J., and Golay, A., 2012. Dance therapy improves self-body image among obese patients. Patient Education and Counseling, 89 (3), $525-528$ 
North, M., 1972. Personality assessment through movement. London: Macdonald and Evans.

Payne, H., 2006. Introduction: Embodiment in Action. In: H. Payne, ed. Dance Movement Therapy: Theory, Research and Practice. London: Routledge, 1-17.

Petrie, K. and Greenleaf, C., 2011. Body image and athleticism. In: T. Cash and L. Smolak, eds. Body Image: A Handbook of Science, Practice and Prevention (2 ${ }^{\text {nd }}$ ed.). New York: Guilford, 206-214.

Pullen, S.A., Povey, R.C. and Grogan, S.C., 2009. Deciding to attend cardiac rehabilitation: A female perspective. International Journal of Therapy and Rehabilitation, 16 (4), 207-217

Sandel, S.L. et al., 2005. Dance and movement program improves quality-of-life measures in breast cancer survivors. Cancer Nursing, 28 (4), 301-309.

Smith, H., Grogan, S., Davey. R and Cochrane, T., 2009. Developing a successful physical activity intervention in primary school children. Education and Health, 27, 63-66.

Smolak, L., 2012. Appearance in childhood and adolescence. In: N. Rumsey and D. Harcourt, eds. The Oxford Handbook of the Psychology of Appearance. Oxford: Oxford University Press, 123-142.

Smolak, L. and Stein, J.A., 2010. A longitudinal investigation of gender role and muscle building in adolescent boys. Sex Roles, 63 (9-10), 738-746.

Strauss, A. and Corbin, J., 1990. Basics of qualitative research: Grounded theory procedures and techniques. London: Sage. 
Tylka, T.L., and Sabik, N.J., 2010. Integrating social comparison theory and self-esteem within objectification theory to predict women's disordered eating. Sex Roles, 63 $(1-2), 18-31$.

Tykla, T.L., 2011. Positive psychology perspectives on body image. In: T. Cash and L. Smolak, eds. Body Image: A Handbook of Science, Practice and Prevention $\left(2^{\text {nd }}\right.$ ed.). New York: Guilford, 56-67.

Wertheim, E. and Paxton, S.J., 2011. Body image development in adolescent girls. Body Image: A Handbook of Science, Practice and Prevention (2 ${ }^{\text {nd }}$ ed.). New York: Guilford, 76-95.

Wilkinson, S., 2008. Focus Groups. In JA Smith, ed. Qualitative Psychology: A Practical Guide to Research Methods. (2nd ed). London: Sage, 186-207.

Willig, C., 2008. Introducing qualitative research in psychology: Adventures in theory and method ( $2^{\text {nd }}$ ed.). Maidenhead: Open University Press. 


\section{Appendix 1: Time Line of Session}

\section{Viewing of two film clips of young woman dancing from}

\section{http://www,youtube.com/watch?v=kL9HZIhKiZK .}

Aim: To introduce relationship between body image and movement. Two contrasting film clips portraying the mind-body connection and its role in understanding and engaging with features of healthy and unhealthy body image. Clip 1 - movement expressing healthy body image; illustrating that healthy body image is three dimensional, the picture of one's body is experienced fully and each body part feels alive. Movement appears fluid and relaxed and there is freedom of movement throughout the body. Clip 2 - Movement expressing unhealthy body image; illustrating unhealthy body image is two dimensional, the picture of one's body is experienced only partially since areas of the body feel 'dead' and are not as available to consciousness. Movement appears fragmented and stiff and there is restricted movement in some areas of the body. (10 mins).

\section{Introduction: Preliminary movement}

Aim: To create a reference point for encouraging reflection on totality of body experience involved in body image experience. Icebreaker exercise - Name game in a circle with ball. In pairs creating a $2 \mathrm{D}$ body map by drawing around bodies to compare the $2 \mathrm{D}$ vs.3D body image experience. (10 mins).

\section{Body awareness exercises/Body part work}

Aim: To focus on enhancing sensory experience of various body parts and explore participants feelings/attitudes to these areas. To facilitate an exploration of healthy body image as an experience of awareness and acceptance of the whole body. After each 
exercise participants record their experiences on the body map to facilitate a reflective process and encourage developing the mind-body relationship.

Body part 1- Feet. Focusing on sensory experiences through various static and travelling movements aimed at exploring all surfaces of the feet and expression through movement of feelings of connectedness (5 mins).

Body part 2 - Leg. Exploring the connection between body parts (Feet to Leg). Focusing attention through self massage on muscles in calves and thighs. Exerciseswall squat, walking on haunches, ways of propelling. Introducing play as another vehicle for exploring and improving our awareness and connection to our bodies. (5 mins).

Body part 3 - Hips. Exploring the connection between leg and hips. Bringing awareness and movement into the pelvis. Exploring it as a bowl of circles, holes and arches, hip joint supports large \% of body weight, ball and socket joint. Activity Hoola hooping. (5 mins).

Body part 4- Spine. Exploring the connection between hips and spine. Bringing awareness to how weight is transferred from skull through spine into hips. ExerciseWaterfall, rolling and unrolling spine, vertebrae by vertebrae. Figure of eight spine exercise in partners. (5 mins).

Body part 5 - Shoulders and arms. Self massage. Ball and socket shoulder joint rotations, shoulder stretch in pairs (5 mins).

Body part 6 - Hands. Self Massage. Evolved from paws, carry meaning instead of weight. Play on haunches, experiencing hands carrying weight like apes (5 mins).

\section{Exercises to explore the movement quality of weight}


Aim: To explore bodily felt experiences of weight when engaged in different movement tasks. Increasing awareness of the subjective nature of this experience and the importance of the mind body connection in our experience of body image. Strong weight exercises - Wall moves, lycra exercise. Light weight exercises - The breath, giant balloons. (5 mins).

\section{Whole body micro scan}

Cool down (5 mins). 